\title{
Effect of Dietary Nori (Dried Laver) on Blood Pressure in Young Japanese Children: An Intervention Study
}

\author{
Keiko Wada ${ }^{1}$, Michiko Tsuji ${ }^{1,2}$, Kozue Nakamura ${ }^{1,3}$, Shino Oba ${ }^{1,4}$, Sakiko Nishizawa ${ }^{5}$, \\ Keiko Yamamoto ${ }^{5}$, Kaori Watanabe ${ }^{5}$, Kyoko Ando $^{5}$, and Chisato Nagata ${ }^{1}$ \\ ${ }^{1}$ Department of Epidemiology and Preventive Medicine, Gifu University Graduate School of Medicine, Gifu, Japan \\ ${ }^{2}$ Department of Food Science and Nutrition, Nagoya Women's University, Nagoya, Japan \\ ${ }^{3}$ Gifu City Healthcare Center, Gifu, Japan \\ ${ }^{4}$ Graduate School of Health Sciences, Gunma University, Maebashi, Japan \\ ${ }^{5}$ Department of Food and Culture Science, Aichi Bunkyo Women's College, Aichi, Japan
}

Received July 30, 2019; accepted December 6, 2019; released online March 21, 2020

\begin{abstract}
Background: Few studies have examined the association between seaweed intake and blood pressure in children. We conducted an intervention study to investigate whether seaweed intake affects blood pressure.

Methods: Subjects were children aged 4 to 5 years attending a preschool in Aichi Prefecture, Japan, in 2010. Among 99 students, 89 (89.9\%) were enrolled in our study. Nori (dried laver), an edible seaweed widely consumed in Japan, was used as a dietary intervention. Children in the intervention group were asked to consume 1.76 grams per day of roasted nori in addition to standard meals for 10 weeks. Children in the control group consumed their usual diet. Before the intervention and at the 10th week of the intervention, children's blood pressure was measured three times successively using an automated sphygmomanometer with subjects in a sitting position. Changes in systolic (SBP) and diastolic blood pressure (DBP) were compared between 55 children in the intervention group and 26 in the control group after adjustment for SBP and DBP before the intervention.

Results: Changes in SBP were $-8.29 \mathrm{~mm} \mathrm{Hg}$ in the intervention group and $+0.50 \mathrm{~mm} \mathrm{Hg}$ in the control group $(P$ for difference in change $=0.051$ ). Changes in DBP were $-6.77 \mathrm{~mm} \mathrm{Hg}$ in the intervention group and $-0.05 \mathrm{~mm} \mathrm{Hg}$ in the control group $(P=0.031)$. In girls, no difference in blood pressure changes was found between the intervention and control groups.

Conclusion: Nori intake lowered DBP level in boys. Seaweed intake might have preventive effects on elevated blood pressure in childhood.
\end{abstract}

Key words: blood pressure; child; laver; nutrition; seaweed

Copyright $\odot 2020$ Keiko Wada et al. This is an open access article distributed under the terms of Creative Commons Attribution License, which permits unrestricted use, distribution, and reproduction in any medium, provided the original author and source are credited.

\section{INTRODUCTION}

Several studies have shown that blood pressure is linked over time from childhood to adulthood and that atherogenesis begins in childhood. ${ }^{1-3}$ Increased blood pressure is an established risk factor of cardiovascular disease, which is a major cause of death among Japanese adults. ${ }^{4,5}$ In addition, many lifestyle habits tend to track across childhood and into adulthood. ${ }^{6,7}$ Thus, identifying modifiable determinants of elevated blood pressure early in life may contribute to preventing hypertension in later adulthood.

Restricted salt and alcohol consumption and increased intake of potassium, fiber, fruits, and vegetables have been reported to reduce blood pressure among adults. ${ }^{8-10}$ Salt intake has been considered a contributor to elevated blood pressure in children and adolescents; however, the role of other dietary factors in blood pressure remains unclear. ${ }^{11-14}$ We previously reported that seaweed intake was inversely associated with diastolic blood pressure (DBP) among boys and with systolic blood pressure (SBP) among girls in a cross-sectional study of Japanese children aged 3 to 6 years. ${ }^{15}$ There are some reports that dietary patterns that include seaweed-rich foods are associated with lower blood pressure and decreased arterial stiffness. ${ }^{16,17}$ Several experimental studies have also shown that feeding on seaweed or its extracts lowers blood pressure in animals. ${ }^{18-21}$ Alginate extracted from seaweed was reported to attenuate salt-induced hypertension by decreasing cardiovascular and renal damage in rats. ${ }^{22,23}$ Several kinds of peptides with activity against angiotensin I-converting enzyme (ACE I) have been isolated from seaweed. ${ }^{24,25}$ However, few intervention studies have investigated the effects of seaweed intake on blood pressure, ${ }^{26-29}$ and none have been conducted among children.

Here, we conducted an intervention study examining the effect of seaweed intake on blood pressure among preschool-aged Japanese children. Nori (dried laver), an edible seaweed widely consumed in Japan, was chosen as a dietary intervention. 


\section{METHODS}

\section{Study design and participants}

This study was an intervention study conducted from April through July 2010. The study protocol and informed consent procedure were approved by the ethics board of Gifu University Graduate School of Medicine, Gifu, Japan. The study was registered at UMIN clinical trials registry on April 21, 2010 (ID: UMIN000003509).

Subjects were second-year students aged 4-5 years attending a preschool in Aichi Prefecture, Japan. Of 99 children, 89 (89.9\%) agreed to be enrolled in our study, with their parents providing written informed consent.

\section{Randomization and blinding}

Figure 1 shows flow diagram of participants. The preschool had three second-grade classes. Among the three classes, two were randomly assigned as the intervention group (61 children), and the other class was assigned as the control group (28 children). The allocation was conducted using a random number table. Although the trial was basically unblinded, the staff who measured blood pressure were not given information on the group assignment.

\section{Interventions}

The intervention period was 10 weeks. In the intervention group, one pack (1.76 grams/6 sheets) of roasted nori (Yamamotoyama, Tokyo, Japan) was served to children in addition to standard meals at school lunch. Roasted nori is a dried seaweed snack that is often consumed alone or with rice in Japan and is generally popular among Japanese children. With the popularization of sushi, nori is becoming more widely consumed in Western countries. The nori given to study participants was made of red seaweed cultivated in the Ariake Sea near the island of Kyushu in southern Japan and did not contain salt or other flavorings. Study staff and preschool teachers encouraged the children to eat all of

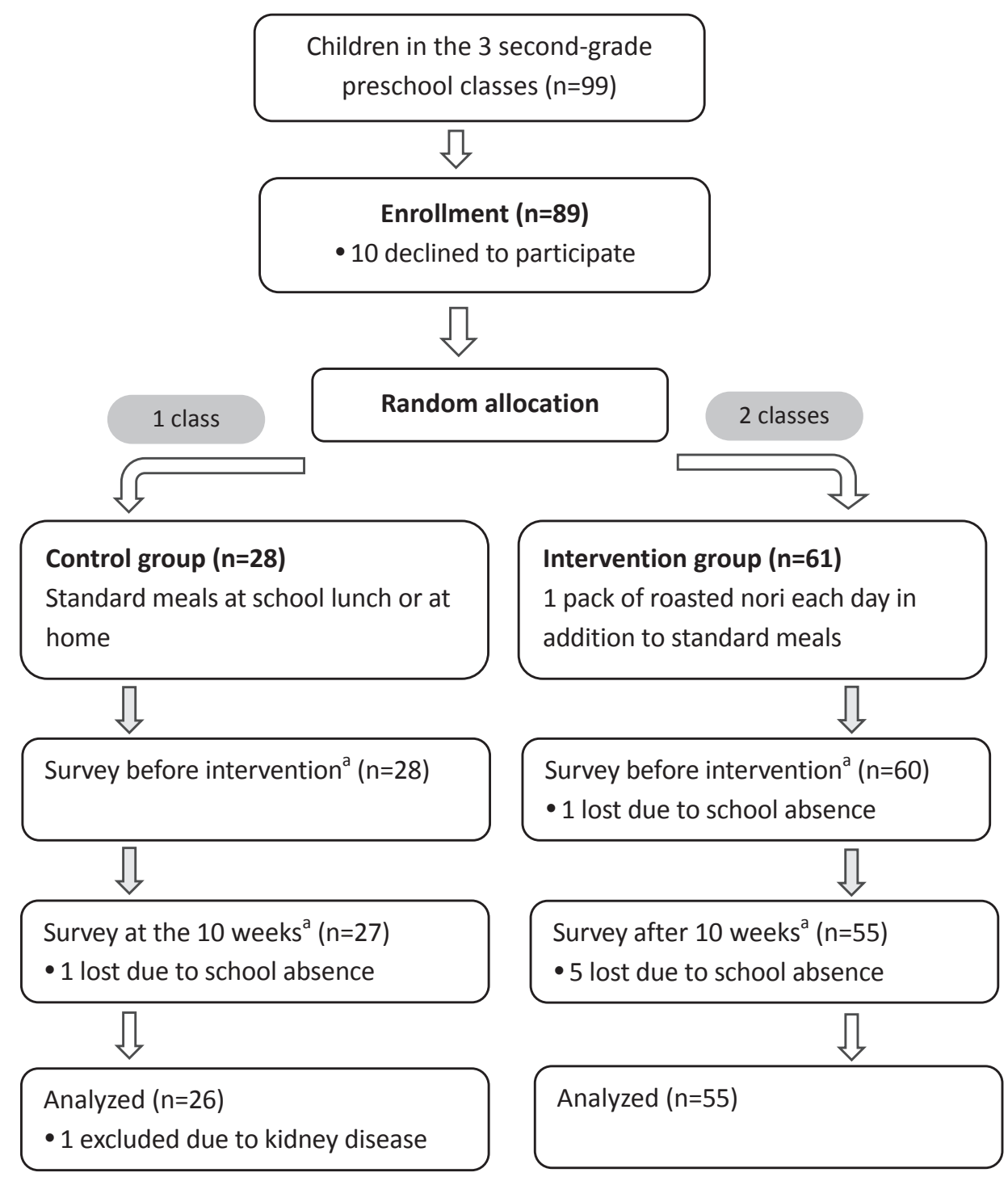

${ }^{a}$ Measurement of blood pressure, height, and weight, response to a questionnaire, and dietary record.

Figure 1. Flow diagram of participants 
their lunch foods, including nori, every day. On weekends, children were asked to eat one pack of nori each day at home. In the control group, nothing was added to meals at school lunch or at home.

\section{Examination}

Before the intervention and at the 10th week of the intervention, participant height, weight, and blood pressure were measured. In addition, children's health status and lifestyle were assessed through a parent-administered questionnaire. Nutritional data, including seaweed intake, were also collected using 3-day dietary records covering 2 consecutive weekdays and 1 weekend day.

\section{Blood pressure and other measurements}

SBP, DBP, and heart rate were measured using an automated sphygmomanometer (ES-H55; Terumo Co., Tokyo, Japan) with oscillometer methods. Measurements were taken midmorning three times successively on the upper arm, using an appropriately sized cuff based on each child's arm circumference and with subjects in a sitting position after a few minutes of rest. The means of these measurements were used for analysis. Body mass index (BMI) was calculated as (weight in $\mathrm{kg}$ )/(height in $\mathrm{m})^{2}$.

\section{Dietary record and questionnaire}

Parents were given written instructions for recording their children's food intake and recorded the amounts and types of foods and beverages their children consumed during each of the 3 days. If parents had difficulty with recording, our staff assisted them by phone. For school lunches and snacks during the 2 weekdays, dieticians checked meals provided by the preschool and measured the quantity of food each child had left over. Individual nutrient intake was estimated using the Japanese Standard Table of Food Composition, 5th Revised and Enlarged Edition. ${ }^{30}$ According to the nutrient density method, carbohydrate, protein, and fat intake were presented as \% of total energy. The other nutrient intakes were presented as grams per 1,000 kcal of total energy.

Child's birth weight, present illness, and use of medicine were inquired in a parent-administered questionnaire. Information on child's lifestyles, including sleep, screen viewing, and reading, and smoking habits of family members was also obtained from the questionnaire. Sleep duration at night was calculated as the time from bedtime to wake-up time. Sedentary lifestyle time was defined as the sum of the time children spent watching television, playing video games, or reading. Household smoking was defined as exposure to tobacco smoke due to one or more family members regularly smoking at home.

\section{Sample size}

For power analysis, we used a standard deviation of $11 \mathrm{~mm} \mathrm{Hg}$ in blood pressure from our previous cross-sectional study of preschool children. ${ }^{15}$ Because there was no similar intervention study among children, we estimated $8 \mathrm{~mm} \mathrm{Hg}$ decrease in blood pressure based on a previous study of hypertensive Japanese patients in which differences in blood pressure change were 5-10 $\mathrm{mm} \mathrm{Hg}$ between the intervention and control groups after intake of $5 \mathrm{~g} /$ day of seaweed (wakame) powder. ${ }^{27}$ When randomization of 2:1 for the intervention and control group were considered, we calculated that with total sample of 69 participants, the study would have $80 \%$ power to detect the difference in blood pressure with a type I error of $5 \%$.

\section{Statistical analysis}

Complete measurement data were obtained for 82 children (Figure 1). After one child with kidney disease was excluded, 55 children in the intervention group and 26 in the control group were analyzed. None of participants had history of or medicine use for hypertension.

Analyses were conducted using SAS 9.4 (SAS Institute, Cary, NC, USA) and were stratified by sex. All $P$-values were calculated using a two-sided test. A significant difference was defined as $P<0.05$.

Subject characteristics before the intervention were summarized for the intervention and control groups (Table 1). Means and proportions were compared between groups using $t$-test and chi-squared test, respectively. Blood pressure levels and seaweed intake were not different between the intervention and control groups. Boys in the control group were taller than those in the intervention group $(P=0.018)$. Girls in the control group had higher fat intake than did those in the intervention group $(P=0.010)$.

To assess the effect of nori intake on blood pressure levels, we compared changes in SBP and DBP between the intervention and control groups by one-way analysis of covariance. Because blood pressure levels before the intervention would likely be associated with the changes afterward, SBP and DBP before the study were controlled for (model 1). As a sensitivity analysis, additional adjustment for height and fat intake was conducted (model 2), because the differences in these variables observed between the intervention and control groups.

\section{RESULTS}

In boys, SBP decreased by $8.29 \mathrm{~mm} \mathrm{Hg}$ from before the intervention to the 10th week of the intervention in the intervention group, while an increase of $0.50 \mathrm{~mm} \mathrm{Hg}$ was observed in the control group $(P$ for difference in change $=0.051)($ model 1$)$ (Table 2). The changes in DBP level were $-6.77 \mathrm{~mm} \mathrm{Hg}$ in the intervention group and $-0.05 \mathrm{~mm} \mathrm{Hg}$ in the control group $(P=0.031)$. In girls, no difference in blood pressure changes was found between the intervention and control groups ( $P$ for $\mathrm{SBP}=0.85$ and $P$ for $\mathrm{DBP}=0.27)$. In sensitivity analyses adjusting additionally for height and fat intake, the difference in DBP changes remained significant between in the intervention group and in the control group among boys $(P=0.014)$.

Except for nori supplied by study staff, seaweed intake at the 10th week of the intervention was not different between the intervention and control groups in either boys or girls. For boys in the intervention group, total energy intake decreased by $111.3 \mathrm{kcal} / \mathrm{d}$ from before the intervention to the 10th week, while such a change was not observed in the control group $(P$ for difference in change $=$ 0.063). After additional adjustment for the change in total energy intake from before the intervention to the 10th week of the intervention, changes in DBP were $-7.37 \mathrm{~mm} \mathrm{Hg}$ in the intervention group and $1.48 \mathrm{~mm} \mathrm{Hg}$ in the control group $(P=0.017)$.

Three children reported the use of medicine with a sympathomimetic effect, such as tulobuterol hydrochloride and DL-methylephedrine hydrochloride, for treatment of a cold during the study period. Results were not substantially altered when these subjects were excluded from the analysis. For example, the changes in DBP from before the intervention to the 10th week were $-6.70 \mathrm{~mm} \mathrm{Hg}$ in the intervention group and $0.11 \mathrm{~mm} \mathrm{Hg}$ in the control group $(P=0.033)$ (model 1$)$. 
Effect of Seaweed Intake on Blood Pressure in Children

Table 1. Characteristics of subjects in the intervention and control groups before the intervention

\begin{tabular}{|c|c|c|c|c|c|c|c|c|c|c|}
\hline \multirow[b]{3}{*}{$n$} & \multicolumn{4}{|l|}{ Boys } & \multirow{3}{*}{$P^{\mathrm{a}}$} & \multicolumn{4}{|l|}{ Girls } & \multirow{3}{*}{$P^{\mathrm{a}}$} \\
\hline & \multicolumn{2}{|l|}{ Control } & \multicolumn{2}{|c|}{ Intervention } & & \multicolumn{2}{|l|}{ Control } & \multicolumn{2}{|c|}{ Intervention } & \\
\hline & 11 & & 28 & & & 15 & & 27 & & \\
\hline Age, years & 4.5 & $(0.3)$ & 4.5 & $(0.3)$ & 0.87 & 4.5 & $(0.3)$ & 4.5 & $(0.3)$ & 0.91 \\
\hline Height, $\mathrm{cm}$ & 105.7 & (3.9) & 102.1 & (4.2) & 0.018 & 101.5 & (4.9) & 102.5 & (4.5) & 0.53 \\
\hline Weight, kg & 17.5 & $(2.1)$ & 16.4 & (1.6) & 0.092 & 16.6 & (2.3) & 16.3 & $(1.8)$ & 0.67 \\
\hline Body mass index, $\mathrm{kg} / \mathrm{m}^{2}$ & 15.6 & $(1.1)$ & 15.7 & $(0.8)$ & 0.68 & 16.0 & (1.1) & 15.5 & $(0.9)$ & 0.10 \\
\hline Systolic blood pressure, $\mathrm{mm} \mathrm{Hg}$ & 102.7 & $(9.2)$ & 100.2 & $(10.9)$ & 0.51 & 100.3 & (11.6) & 100.5 & (11.4) & 0.96 \\
\hline Diastolic blood pressure, $\mathrm{mm} \mathrm{Hg}$ & 65.8 & $(13.1)$ & 60.6 & (9.4) & 0.17 & 60.4 & $(10.1)$ & 60.0 & (8.7) & 0.87 \\
\hline Heart rate, beats/min & 93.7 & (12.4) & 88.9 & $(15.7)$ & 0.37 & 91.4 & (12.4) & 94.4 & $(8.2)$ & 0.37 \\
\hline Birth weight, g & $3,310.8$ & (486.3) & $3,028.2$ & $(544.7)$ & 0.14 & $2,925.5$ & (711.8) & $3,139.5$ & (483.2) & 0.25 \\
\hline Present illness, $\%$ & $18.2 \%$ & & $14.8 \%$ & & 0.80 & $20.0 \%$ & & $14.8 \%$ & & 0.67 \\
\hline Medicine use, $\%$ & $30.0 \%$ & & $28.6 \%$ & & 0.93 & $14.3 \%$ & & $26.9 \%$ & & 0.36 \\
\hline Household smoking, $\%$ & $45.5 \%$ & & $71.4 \%$ & & 0.13 & $60.0 \%$ & & $70.4 \%$ & & 0.49 \\
\hline Sleep time at night, $\mathrm{h}$ & 10.1 & $(0.5)$ & 10.0 & $(0.6)$ & 0.52 & 10.0 & $(0.5)$ & 10.2 & $(0.5)$ & 0.44 \\
\hline Sedentary lifestyle time, minutes & 100.5 & $(42.1)$ & 122.5 & (61.4) & 0.28 & 127.3 & $(75.4)$ & 100.9 & $(42.0)$ & 0.15 \\
\hline \multicolumn{11}{|l|}{ Dietary intake } \\
\hline Total energy, $\mathrm{kcal} / \mathrm{d}$ & $1,391.3$ & $(184.5)$ & $1,349.5$ & $(229.2)$ & 0.59 & $1,365.2$ & (198.5) & $1,314.7$ & $(160.1)$ & 0.37 \\
\hline Carbohydrate, $\%$ energy & 55.55 & (4.9) & 56.77 & (4.9) & 0.49 & 54.63 & (4.2) & 57.30 & (4.4) & 0.063 \\
\hline Protein, \% energy & 13.36 & (1.6) & 12.28 & $(2.1)$ & 0.13 & 12.24 & (1.3) & 12.99 & $(1.1)$ & 0.052 \\
\hline Fat, \% energy & 30.03 & (4.1) & 29.80 & (3.9) & 0.87 & 32.26 & $(4.0)$ & 28.83 & (3.8) & 0.010 \\
\hline Salt, g/1000 kcal/d & 3.53 & $(0.4)$ & 3.28 & (0.6) & 0.20 & 3.41 & (0.7) & 3.63 & (0.6) & 0.32 \\
\hline Seaweed, $\mathrm{g} / 1000 \mathrm{kcal} / \mathrm{d}$ & 1.4 & (1.1) & 1.1 & $(1.2)$ & 0.43 & 1.0 & $(0.9)$ & 1.2 & $(0.7)$ & 0.41 \\
\hline Seaweed, once/day or more, $\%$ & $27.3 \%$ & & $32.1 \%$ & & 0.77 & $20.0 \%$ & & $18.5 \%$ & & 0.91 \\
\hline Roasted laver, once/day or more, $\%$ & $18.2 \%$ & & $14.3 \%$ & & 0.76 & $6.7 \%$ & & $3.7 \%$ & & 0.67 \\
\hline
\end{tabular}

mean (standard deviation) or percentage.

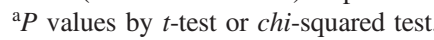

Table 2. Blood pressure levels among the intervention and control groups

\begin{tabular}{|c|c|c|c|c|c|c|c|c|c|}
\hline & \multicolumn{3}{|c|}{ Blood pressure } & \multicolumn{6}{|c|}{ Change in blood pressure } \\
\hline & \multirow{2}{*}{$n$} & \multirow{2}{*}{ before } & \multirow{2}{*}{ after 10 weeks } & \multicolumn{2}{|l|}{ crude } & \multicolumn{2}{|c|}{ model 1} & \multicolumn{2}{|c|}{ model 2} \\
\hline & & & & mean & SE & mean & SE & mean & SE \\
\hline \multicolumn{10}{|l|}{ Boys } \\
\hline \multicolumn{10}{|l|}{ SBP } \\
\hline control & 11 & 102.7 & 102.0 & -0.76 & 4.23 & 0.50 & 3.67 & -0.46 & 4.01 \\
\hline intervention & 28 & 100.2 & 92.4 & -7.80 & 2.65 & -8.29 & 2.30 & -7.92 & 2.41 \\
\hline \multirow{2}{*}{\multicolumn{10}{|c|}{ DBP }} \\
\hline & & & & & & & & & \\
\hline intervention & 28 & 60.6 & 54.7 & -5.92 & 1.91 & $\begin{array}{l}-0.05 \\
-6.77\end{array}$ & $\begin{array}{l}2.31 \\
1.56\end{array}$ & $\begin{array}{l}1.25 \\
-7.28\end{array}$ & $\begin{array}{l}2.10 \\
1.60\end{array}$ \\
\hline$P^{\mathrm{a}}$ & & & & 0.31 & & 0.031 & & 0.014 & \\
\hline \multicolumn{10}{|l|}{ Girls } \\
\hline \multicolumn{10}{|l|}{ SBP } \\
\hline control & 15 & 100.3 & 97.3 & -3.07 & 2.91 & -3.13 & 2.39 & -2.46 & 2.59 \\
\hline intervention & 27 & 100.5 & 97.9 & -2.60 & 2.17 & -2.57 & 1.78 & -2.94 & 1.88 \\
\hline$P^{\mathrm{a}}$ & & & & 0.90 & & 0.85 & & 0.89 & \\
\hline \multicolumn{10}{|l|}{ DBP } \\
\hline control & 15 & 60.4 & 56.2 & -4.29 & 2.65 & -4.05 & 1.96 & -3.91 & 2.14 \\
\hline intervention & 27 & 60.0 & 58.8 & -1.16 & 1.98 & -1.29 & 1.46 & -1.37 & 1.55 \\
\hline$P^{\mathrm{a}}$ & & & & 0.35 & & 0.27 & & 0.37 & \\
\hline
\end{tabular}

DBP, diastolic blood pressure; SBP, systolic blood pressure; SE, standard error.

${ }^{a} P$ value by analysis of variance or analysis of covariance.

model 1: adjustment for blood pressure level (SBP or DBP) before the intervention.

model 2: adjustment for blood pressure level (SBP or DBP) before the intervention, height, and fat intake.

\section{DISCUSSION}

To our knowledge, this is the first intervention study to suggest that seaweed consumption has beneficial effects on blood pressure among healthy children. We observed that addition of 1.76 grams per day of nori to the diet over 10 weeks significantly decreased DBP in boys. Four previous intervention studies on seaweed intake and blood pressure have been conducted among adults. A decrease in mean blood pressure was observed among Swedish patients with mild hypertension given 12 and $24 \mathrm{~g}$ /day of seaweed fiber for 4 weeks compared with placebo treatment. ${ }^{26}$ In hypertensive Japanese patients, SBP and DBP decreased 
compared with the control group after intake of $5 \mathrm{~g} /$ day of seaweed (wakame) powder for 8 weeks. ${ }^{27}$ Among patients with high blood pressure in Ecuador, a decrease in SBP from baseline was observed after intake of $4 \mathrm{~g} /$ day of dried seaweed (wakame) for 4 weeks and followed by $6 \mathrm{~g}$ /day for 4 weeks, although comparison with a placebo group was not shown. ${ }^{28}$ Another uncontrolled intervention study reported that nori-derived peptide intake of $1.8 \mathrm{~g} /$ day induced a significant blood pressure reduction in hypertensive but not normotensive subjects. ${ }^{29}$ Although these results suggest that seaweed consumption may help prevent increased blood pressure, further studies are warranted to confirm the anti-hypertensive effects of seaweed intake.

Peptides derived from Pyropia yezoensis have been shown to have ACE I inhibitory activity and hypotensive effects. ${ }^{29,31}$ Porphyran, a main constituent of Pyropia yezoensis, potentially has antioxidant activity. ${ }^{25}$ It is likely that these unique biologically active compounds of nori play an important role on reducing blood pressure, although we could not identify a causative factor in this dietary intervention. Nori also has high contents of dietary fiber, protein, minerals, vitamins, and polyunsaturated fatty acids. ${ }^{30,32}$ Protein content in red and green seaweed is generally higher than that in brown seaweed, which is much greater than that found in high-protein legumes, such as soybeans. ${ }^{32}$ The mineral content of seaweed is higher than that of most land vegetables. ${ }^{32}$ It is possible that calcium and magnesium, as well as potassium, are responsible for lowering blood pressure. ${ }^{33}$ Nori is also known to contain abundant vitamin B12 and folic acid, whereas other edible seaweeds contain little or none of these vitamins. Folic acid may reduce homocysteine level and improve endothelial function, resulting in reduced blood pressure. ${ }^{34,35}$ Nori is particularly rich in eicosapentaenoic acids, which have beneficial effects on cellular and molecular mechanisms of atherosclerosis. ${ }^{36}$ The combined intake of these components in seaweed might exert positive effects on blood pressure.

Although our previous cross-sectional study showed an inverse association between seaweed intake and SBP in girls, a blood pressure-lowering effect of seaweed intake was not observed in girls in this intervention study. Considering that a longer-term diet was evaluated in the cross-sectional study, it is possible that more time is required for seaweed intake to influence blood pressure in girls; however, longitudinal studies on daily seaweed intake would be required to confirm this. Although our findings also suggest a sex difference in the effects of seaweed intake on blood pressure, the mechanisms are unknown. As the release of vasopressin and aldosterone induced by angiotensin II and the fluid intake response to angiotensin II were reported to differ by sex, ${ }^{37}$ the effect of nori-derived peptides on the renin-angiotensinaldosterone system may also be influenced by sex.

The merits of our study include the interventional design, high participation rate, repeated measurement of blood pressure, and use of dietary records. Because the nori intake intervention was done at school lunch in the presence of teachers and study staff, most children consumed the nori as directed. However, we were not able to guarantee the completeness of nori intake on weekends. In addition, the nori trial was unblinded for study subjects. Because we randomly allocated the intervention or control groups to the units of school class, but not to individual children, differences in some characteristics (height and fat intake) were observed between the intervention and control groups. However, the results were not substantially altered after additional adjustment for height and fat intake. We could not verify the effect of nori using the other designs, such as a crossover study. Finally, we need to be cautious of comparing the values of blood pressure we observed with those of previous studies, because the methods, devices, and environment of measurement may affect the values. ${ }^{38}$ In addition, the data of blood pressure measurements is still scarce among preschool Japanese children. ${ }^{15,35,39-41}$

In conclusion, this intervention study showed that nori intake lowered DBP in boys aged 4 to 5 years. Although our findings suggest that seaweed intake potentially decreases blood pressure in childhood, future prospective research is needed to determine the preventive effects of seaweed intake early in life on hypertension in later adulthood.

\section{ACKNOWLEDGEMENTS}

This work was supported by a grant-in-aid (grant number 21890093) from the Ministry of Education, Culture, Sports, Science and Technology of Japan.

Conflicts of interest: None declared.

\section{REFERENCES}

1. Chen X, Wang Y. Tracking of blood pressure from childhood to adulthood: a systematic review and meta-regression analysis. Circulation. 2008;117:3171-3180.

2. Berenson GS, Srinivasan SR, Bao W, Newman WP 3rd, Tracy RE, Wattigney WA. Association between multiple cardiovascular risk factors and atherosclerosis in children and young adults. The Bogalusa Heart Study. N Engl J Med. 1998;338:1650-1656.

3. Beauloye V, Zech F, Tran HT, Clapuyt P, Maes M, Brichard SM Determinants of early atherosclerosis in obese children and adolescents. J Clin Endocrinol Metab. 2007;92:3025-3032.

4. Fujiyoshi A, Ohkubo T, Miura K, et al; Observational Cohorts in Japan (EPOCH-JAPAN) Research Group. Blood pressure categories and long-term risk of cardiovascular disease according to age group in Japanese men and women. Hypertens Res. 2012;35(9):947-953.

5. Ministry of Health, Labour and Welfare. Vital Statistics in JAPAN 2017. [homepage on the Internet]. Available from: https://www. mhlw.go.jp/toukei/saikin/hw/jinkou/kakutei17/index.html.

6. Mikkilä V, Räsänen L, Raitakari OT, Pietinen P, Viikari J. Consistent dietary patterns identified from childhood to adulthood: the cardiovascular risk in Young Finns Study. Br J Nutr. 2005;93(6): 923-931.

7. Telama R, Yang X, Leskinen E, et al. Tracking of physical activity from early childhood through youth into adulthood. Med Sci Sports Exerc. 2014;46:955-962.

8. Intersalt Cooperative Research Group. Intersalt: an international study of electrolyte excretion and blood pressure. Results for 24 hour urinary sodium and potassium excretion. BMJ. 1988;297:319-328.

9. John JH, Ziebland S, Yudkin P, Roe LS, Neil HA; Oxford Fruit and Vegetable Study Group. Effects of fruit and vegetable consumption on plasma antioxidant concentrations and blood pressure: a randomised controlled trial. Lancet. 2002;359(9322):1969-1974.

10. Streppel MT, Arends LR, van 't Veer P, Grobbee DE, Geleijnse JM. Dietary fiber and blood pressure: a meta-analysis of randomized placebo-controlled trials. Arch Intern Med. 2005;165:150-156.

11. He FJ, MacGregor GA. Importance of salt in determining blood pressure in children: meta-analysis of controlled trials. Hypertension. 2006;48:861-869.

12. Yang Q, Zhang Z, Kuklina EV, et al. Sodium intake and blood pressure among US children and adolescents. Pediatrics. 2012;130: 611-619.

13. Falkner B. Does potassium deficiency contribute to hypertension in children and adolescents? Curr Hypertens Rep. 2017;19:37. 
14. Collese TS, Nascimento-Ferreira MV, de Moraes ACF, et al. Role of fruits and vegetables in adolescent cardiovascular health: a systematic review. Nutr Rev. 2017;75:339-349.

15. Wada K, Nakamura K, Tamai Y, et al. Seaweed intake and blood pressure levels in healthy pre-school Japanese children. Nutr J. 2011;10:83.

16. Osonoi Y, Mita T, Osonoi T, et al. Relationship between dietary patterns and risk factors for cardiovascular disease in patients with type 2 diabetes mellitus: a cross-sectional study. Nutr J. 2016;15:15.

17. Moyama S, Minami K, Yano M, et al. Relationship between dietary patterns and brachial-ankle pulse wave velocity among middle-aged adults in Japan. Asia Pac J Clin Nutr. 2017;26:539-544.

18. Yamori Y, Nara Y, Tsubouchi T, Sogawa Y, Ikeda K, Horie R. Dietary prevention of stroke and its mechanisms in stroke-prone spontaneously hypertensive rats-preventive effect of dietary fibre and palmitoleic acid. J Hypertens Suppl. 1986;4:S449-S452.

19. Sato M, Oba T, Yamaguchi T, et al. Antihypertensive effects of hydrolysates of wakame (Undaria pinnatifida) and their angiotensinI-converting enzyme inhibitory activity. Ann Nutr Metab. 2002;46: 259-267.

20. Fitzgerald C, Aluko RE, Hossain M, Rai DK, Hayes M. Potential of a renin inhibitory peptide from the red seaweed Palmaria palmata as a functional food ingredient following confirmation and characterization of a hypotensive effect in spontaneously hypertensive rats. J Agric Food Chem. 2014;62:8352-8356.

21. Kumar SA, Magnusson M, Ward LC, Paul NA, Brown L. Seaweed supplements normalise metabolic, cardiovascular and liver responses in high-carbohydrate, high-fat fed rats. Mar Drugs. 2015;13:788805.

22. Moriya C, Shida Y, Yamane Y, et al. Subcutaneous administration of sodium alginate oligosaccharides prevents salt-induced hypertension in Dahl salt-sensitive rats. Clin Exp Hypertens. 2013;35: 607-613.

23. Terakado S, Ueno M, Tamura $\mathrm{Y}$, et al. Sodium alginate oligosaccharides attenuate hypertension and associated kidney damage in Dahl salt-sensitive rats fed a high-salt diet. Clin Exp Hypertens. 2012;34:99-106.

24. Seca AML, Pinto DCGA. Overview on the antihypertensive and anti-obesity effects of secondary metabolites from seaweeds. Mar Drugs. 2018;16(7):E237.

25. Venkatraman KL, Mehta A. Health benefits and pharmacological effects of Porphyra species. Plant Foods Hum Nutr. 2019;74:10-17.

26. Krotkiewski M, Aurell M, Holm G, Grimby G, Szczepanik J. Effects of a sodium-potassium ion-exchanging seaweed preparation in mild hypertension. Am J Hypertens. 1991;4:483-488.

27. Hata Y, Nakajima K, Uchida J, Hidaka H, Nakano T. Clinical effects of brown seaweed, Undaria pinnatifida (wakame), on blood pressure in hypertensive subjects. J Clin Biochem Nutr. 2001;30:43-53.
28. Teas J, Baldeón ME, Chiriboga DE, Davis JR, Sarriés AJ, Braverman LE. Could dietary seaweed reverse the metabolic syndrome? Asia Pac J Clin Nutr. 2009;18(2):145-154.

29. Saito M, Kawai M, Hagino H, et al. Antihypertensive effect of Noripeptides derived from red alga porphyra yezoensis in hypertensive patients. Am J Hypertens. 2002;15:210A.

30. Council for Science and Technology; Ministry of Education, Culture, Sports, Science and Technology, Japan. Standard Tables of Food Composition in Japan. 5th revised and enlarged edition. Tokyo: Kagawa Nutrition University Publishing Division; 2008.

31. Suetsuna K. Purification and identification of angiotensin I-converting enzyme inhibitors from the red alga Porphyra yezoensis. J Mar Biotechnol. 1998;6:163-167.

32. Bocanegra A, Bastida S, Benedí J, Ródenas S, Sánchez-Muniz FJ. Characteristics and nutritional and cardiovascular-health properties of seaweeds. J Med Food. 2009;12(2):236-258.

33. Cunha AR, Umbelino B, Correia ML, Neves MF. Magnesium and vascular changes in hypertension. Int J Hypertens. 2012;2012: 754250 .

34. Wang WW, Wang XS, Zhang ZR, He JC, Xie CL. A meta-analysis of folic acid in combination with anti-hypertension drugs in patients with hypertension and Hyperhomocysteinemia. Front Pharmacol. 2017;8:585.

35. Tamai Y, Wada K, Tsuji M, et al. Dietary intake of vitamin B12 and folic acid is associated with lower blood pressure in Japanese preschool children. Am J Hypertens. 2011;24:1215-1221.

36. Borow KM, Nelson JR, Mason RP. Biologic plausibility, cellular effects, and molecular mechanisms of eicosapentaenoic acid (EPA) in atherosclerosis. Atherosclerosis. 2015;242:357-366.

37. Santollo J. Sex differences in angiotensin II-stimulated fluid intake. Exp Physiol. 2017;102:1380-1384.

38. Pickering TG, Hall JE, Appel LJ, et al. Recommendations for blood pressure measurement in humans and experimental animals: part 1: blood pressure measurement in humans: a statement for professionals from the Subcommittee of Professional and Public Education of the American Heart Association Council on High Blood Pressure Research. Circulation. 2005;111:697-716.

39. Horigome H, Katayama Y, Yoshinaga M, Kato Y, Takahashi H, Sumazaki R. Significant associations among hemostatic parameters, adipokines, and components of the metabolic syndrome in Japanese preschool children. Clin Appl Thromb Hemost. 2012;18:189-194.

40. Igarashi H, Fukushige J, Akazawa K, Nose Y, Ueda K. Blood pressure measurement in preschool children: the Hisayama Study. J Paediatr Child Health. 1997;33:480-483.

41. Hashimoto N, Kawasaki T, Kikuchi T, Uchiyama M. Criteria of normal blood pressure and hypertension in Japanese preschool children. J Hum Hypertens. 1997;11:351-354. 